\title{
Quantitative Methods in Environmental and Visual Quality Mapping and Assessment: A Muskegon, Michigan Watershed Case Study with Urban Planning Implications
}

\author{
Di Lu${ }^{1}$, Jon Burley ${ }^{1}$, Pat Crawford ${ }^{1}$, Robert Schutzki ${ }^{2}$ and Luis Loures ${ }^{3}$ \\ ${ }^{1}$ School of Planning, Design, and Construction \\ ${ }^{2}$ Department of Horticulture, Michigan State University \\ ${ }^{3} \mathrm{CIEO}$ - Research Centre for Spatial and Organizational Dynamics \\ University of Algarve \\ 1,2 USA \\ ${ }^{3}$ Portugal
}

\section{Introduction}

For generations, people have been in pursuit of at least two conflicting goals. On one hand, people seek to make life physically easier. Especially during the past few centuries, the results include the development of new products, ease of transportation, and ease of communications. On the other hand, people have growing concerns about the condition of the natural environment, including water, air, soil, plants, and animals. These concerns even include perceptual values about the quality of the environment such as aesthetics/visual quality. As the human population grows, these competing concerns require thoughtful planning, design, and management to efficiently and effectively facilitate the use and protection of the environment. However, it has been at times, difficult for professionals, governmental agencies, and citizens to develop thoughtful measures and means concerning people's perception and reaction associated with the environment.

Assessing landscape aesthetics and perceived environmental quality are often quite intangible tasks and can be difficult to be described quantitatively. However, investigators around the world have explored approaches to evaluate the value of landscape aesthetics by numerous mathematical methods. In the United States, during the 1970s and 1980s legislative Acts stimulated the evolution of manuals and experiments for assessing and managing landscape resources and scenic quality (Zube et al., 1982). Many governmental institutes and organizations produced manuals and guidelines to assess and manage landscape resources, for example, Visual Management System (VMS) from US Forest Service (USFS, 1973), Visual Resource Management (VRM) from Bureau of Land Management (BLM, 1980), and Landscape Resource Management (LRM) from US Soil Conservation Service (Schauman \& Adams, 1979). Environmental planners and designers are also greatly interested in developing methods and procedures to evaluate and predict 
the visual and ecological quality on wild and scenic rivers, scenic highways, scenic and recreational parks, trials, and wetlands (Burley, 1997).

Visual quality assessment approaches in planning and design facilitate professionals to analyze existing conditions and proposed spatial treatments. The approach often requires the use of photographic images or digital drawings to assess the quality of the environment. Photographs have been tested in many studies, and investigators have demonstrated that photographs could be used as substitutes for site visits, as there was strong concurrence between photos and real landscape by respondents (Boster, 1974; Zube, 1974). In addition to landscape planners and professional resource managers, a significant number of individuals, including ecologists, geographers, environmental experts and psychologists are engaging in landscape perception and assessment research, and all of them have introduced and explored different sets of methods and models from their disciplines. The literature in this area of research has become extensive and vast, beyond the scope of this chapter; however Smardon et al., (1986) and Taylor et al., (1987) provide insightful overviews of the fundamental knowledge base. In general, landscape perception and assessment is often considered as a function of the interaction of humans and the landscape including the urban landscape.

Some scholars have proposed and debated around the existence of four general approaches in understanding and describing landscape perception and quality: the expert paradigm, the psychophysical paradigm, the cognitive paradigm and the experimental paradigm (Taylor et al., 1987). The expert paradigm is founded upon the idea that trained professionals are highly suited to assess landscape quality either heuristically or through contrived indexes that actually have no statistical basis. This approach is highly aligned with the arts and formal art theory of past centuries. This approach is often based upon many normative theories that have little scientific backing. The psychophysical paradigm is a respondent based perception approach where preferences are statistically analyzed with various visual treatments. This approach is much more aligned with the sciences. The psychophysical paradigm contains numerous predictors to quantify environmental preferences, but is often weak in theory (explanations) concerning why certain preferences exist. The cognitive paradigm is in many ways similar to the psychophysical statistical approach but address another set of variables that may be more difficult to construct and establish, such as defining mystery in the landscape. The experience paradigm includes measures of attitudes, feelings, and impressions as one experiences the environment. During the past two decades, variables from the psychophysical, cognitive, and experiential paradigms have been studied together to form a more unified approach. Besides those four fundamental ways to examine landscape quality, there is an increasing trend to engage in mapping these landscape perceptions in both rural and urban contexts in the same manner that one can map other physical attributes. This chapter focuses upon the connections between measuring environmental/visual quality, mapping these qualities, and potential uses.

\section{Mapping visual/environmental quality}

It is suggested that the modern era of visual quality assessment began with a recreation scientist Elwood Shafer and colleagues, concerning their publication of predictive visual quality equations (Shafer, 1969; Shafer et al., 1969; Shafer \& Tooby, 1973) that employed the psychophysical approach. Before this time, the expert approach dominated professional 
practice around the world and the expert approach is still widely used today. Shafer employed contemporary social science research methods to numerically obtain a perception based evaluation of black and while rural landscape photographs. He then measured various properties of the photographs such as the area of water in the image and the perimeter of foreground vegetation, statistically relating several of the properties with the preferences of the respondents. Shafer's equation was then demonstrated in a forest management situation to illustrate the practical application of the research (Brush \& Shafer, 1975). While there were precedents for the spatial representation of visual quality before Brush and Shafer's publication, their map is an important example concerning the quantification of environmental/visual quality (Figure 1). These types of maps portray the predicted respondent impression of similar land-cover and similar surface geomorphological features.

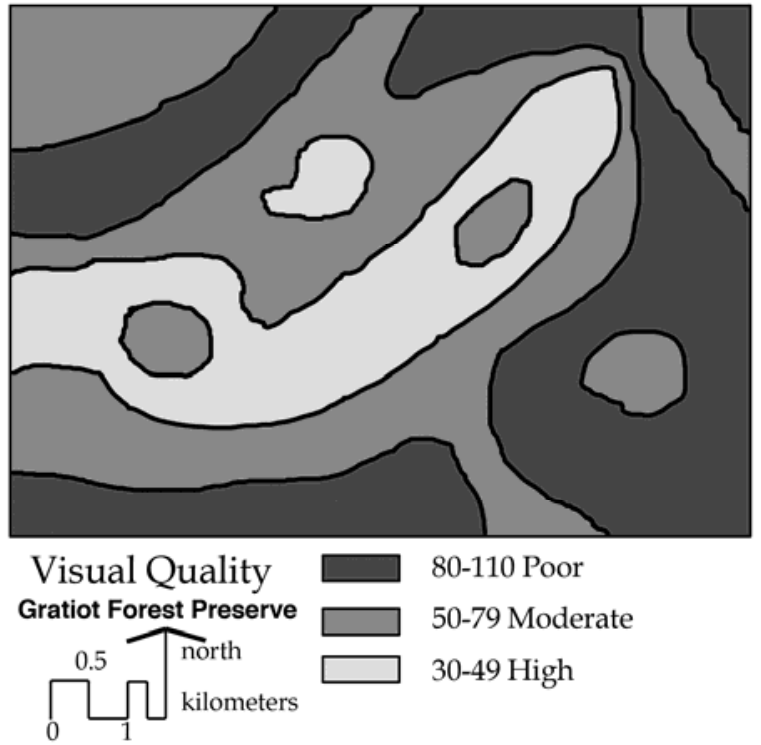

Fig. 1. A map illustrating the general character of maps produced by Brush \& Shafer (1975). Larger numerical scores indicate poor visual quality and lower scores indicated preferred environments.

Any type of work like Shafer's (meaning highly statistical, not based in art theory, or difficult to apply) was highly open to criticism. Shafer's equation was seriously criticized by Bourassa (1991), Carlson (1977), and Wienstein (1976), especially because the statistical model seemed unlinked to any formal, predictive theory to explain the relationships between the physical variables measured in the photographs and the preference ratings of the respondents. Burley (1997:54) notes, "Essentially their criticisms are valid; yet in some respects Shafer and colleagues were somewhat unfairly denounced because engineers, ecologists, economists, and agronomists often gain wide acceptance for developing statistical relationships between variables without having a single theory to explain the relationships, developing a theory is not a prerequisite for developing an equation. 
Nevertheless, Shafer's equation was difficult for some social scientists to accept and investigators examined other directions in environmental landscape preference research. " In many respects it may take years of model testing, theory development, replication, and validation before research is usually accepted; yet this seminal effort seemed not to be widely regarded or fully appreciated. After all, before Shafer's efforts, visual quality experts had little statistical evidence to support their claims, equipped with primarily speculative theories and educated guesses.

Since the creation of the Brush and Shafer map (1975), numerous spatial tools and approaches have been employed to study visual quality mapping. Lu (2011) reviews many of these approaches by investigators applying geographical software systems (GIS), remote sensing tools, digital visualization tools across numerous landscape types from urban settings to rural settings such as Crawford (1994). In addition to Lu's cited sources concerning the mapping of visual quality, Fuente de Val et al., (2006) demonstrated that the heterogeneity of the environment might be an important spatial character in determining visual aesthetic quality for Mediterranean landscapes. Panagopoulos and Vargues (2006) addressed the relevance of using visual maps in golf course development in the Algarve, enabling the assessment of adverse visual impacts of golf courses and the creation of mitigation measures and rehabilitation design alternatives. Arriaza et al., (2004) noted that in Spain, the perceived factors that influence visual quality in rural settings are the degree of wilderness of the landscape, the presence of well-preserved man-made elements, the percentage of plant cover, the amount of water, the presence of mountains and the color contrast. Van den Berg and Koole (2006) suggest that motives in recreational intent influenced respondent preference for environments. In addition, Loures et al., (2008) studied how the use of visual quality maps could influence and improve post-industrial redevelopment. The research activity of these investigators indicate that studies in visual quality landscape assessment continues to increase the knowledge base.

Based upon the literature above, many researchers have explored varied approaches to measure visual quality and make landscape visual quality maps of particular areas. However, there are few experiments to actually validate visual quality maps. The new research presented in this chapter attempts to make a landscape visual quality map of "Lower Muskegon Watershed", which can be also statistically validated. If successful, we believe that we may be entering a new era of visual quality and environmental measurement and monitoring. We believe that the link between spatial visual properties and depictions on maps may be within practical reach.

\section{A recent visual/environmental quality mapping investigation}

Recently we conducted and completed an investigation that is previously unreported in any other publication to see if we could construct and validate a visual quality map in our study area in Michigan, the lower portion of the Muskegon River Watershed (Figure 2). The Muskegon River Watershed is one of the largest watersheds in the State of Michigan and spans across nine counties: Wexford, Missaukee, Roscommon, Osceola, Clare, Mecosta, Montcalm, Newaygo and Muskegon. There are several reasons that the Lower Muskegon Watershed was chosen as the study area: (1) it is composed of several land cover types to study from urban to agricultural and woodland; (2) updated landscape land-use and cover type information was readily available (from 1998); and (3) it is a study area that has 
external construct validity (meaning that the equation can be applied to Michigan) to employ a relatively robust and somewhat predictive equation (Equation 1), that is several generations and iterations from the seminal efforts of Shafer.

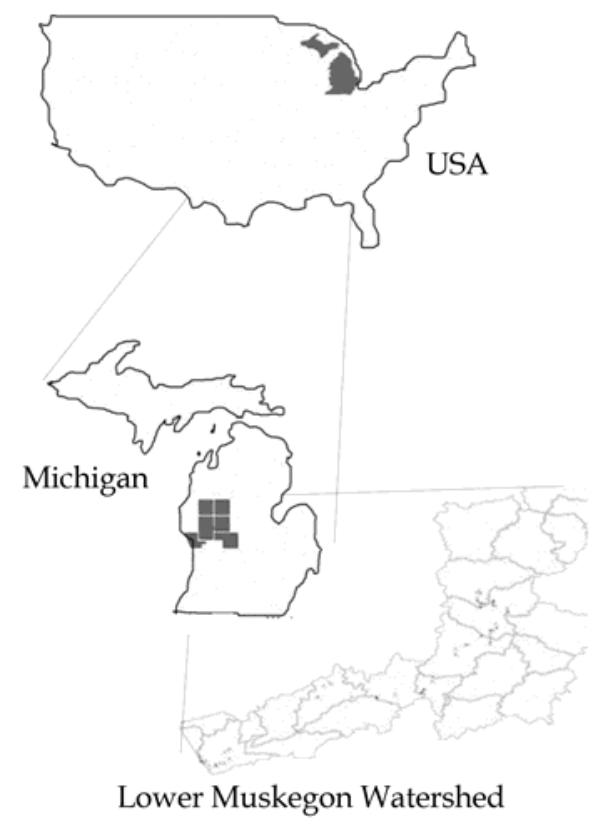

Fig. 2. A series of imbedded maps illustrating the location of the study area, the Lower Muskegon Watershed.

Photographs were collected in this study on the Lower Muskegon Watershed in May and August of 2010. A total of 131 photographs from Lower Muskegon Watershed were recorded, and each of them was positioned and tagged on the map of Lower Muskegon Watershed by Global Positioning System (GPS). The objectives and principles to collect photographs was guided by trying to obtain different types of environments across the study area. The images contain physical attributes such as people, wildlife, water, roads, flowers, vegetation, buildings, industrial facilities, urban savanna, farmland, forest, lakes and rivers. Two sets of 30 photos were chosen from the original 131 photos to analyze. One set to create a predictive map and the other to validate or refute the predictive map by applying a statistical procedure to compare the second set of images with the predicted scores based upon the generated map of visual quality scores.

The basic GIS raster data in this study were downloaded from an Arc GIS database from Grand Valley State University, containing 1998 land-use data. The project of "Sustainable Futures for the Muskegon River Watershed" from Grand Valley State University provides all the "Updated 1998 Land Use Data" in Lower Muskegon Watershed of six counties: Muskegon, Lake, Mecosta, Montcalm, Newaygo, and Osceola counties. By merging all the land use data of these counties, a land-use map of Lower Muskegon Watershed was generated. 
This study utilized Burley's experimental method (Burley, 1997; Lee \& Burley, 2008) to measure the variables of the photos (which uses a grid of 30 rows and 38 columns). Each of the 30 photos from set one and set two were measured according to Equation 1 by Burley (1997), which is based on physical variables and environmental quality index. The equation explains 67 percent of respondent preference, has all predictors with a $p \leq 0.05$ and is not over-specific despite having a fair number of predictor variables. The equation contains an overall p-value of $\leq 0.0001$. This equation is representative of the current state-of-the art in constructing visual/environmental quality predictive models, where a set of regressors explain between 50 and $70 \%$ of respondent's preference. In the future it is expected investigators may improve the predictive power of visual quality/environmental quality equations by exploring new variables, by expanding the number of the images studied, and increasing the number of respondents studied.

$$
\begin{aligned}
& Y=68.30-\left(1.878^{*} \text { HEALTH }\right)-\left(0.131^{*} X 1\right)-\left(0.064^{*} X 6\right)+\left(0.020^{*} X 9\right)+ \\
& \left(0.036^{*} X 10\right)+\left(0.129^{*} X 15\right)-\left(0.129^{*} X 19\right)-\left(0.006^{*} X 32\right)+\left(0.00003^{*} X 34\right)+ \\
& \left(0.032^{*} X 52\right)+\left(0.0008^{*} X 1^{*} X 1\right)+\left(0.00006^{*} X 6^{*} X 6\right)-\left(0.0003^{*} X 15^{*} X 15\right)+ \\
& \left(0.0002^{*} X 19^{*} X 19\right)-\left(0.0009^{*} X 2^{*} X 14\right)-\left(0.00003^{*} X 52^{*} X 52\right)-\left(0.0000001^{*} X 52^{*} X 34\right)
\end{aligned}
$$

Where:

HEALTH= environmental quality index (Table 1)

$\mathrm{X} 1=$ perimeter of immediate vegetation

$\mathrm{X} 2=$ perimeter of intermediate non-vegetation

$\mathrm{X} 3=$ perimeter of distant vegetation

$X 4=$ area of intermediate vegetation

$\mathrm{X} 6=$ area of distant non-vegetation

$X 7=$ area of pavement

$\mathrm{X} 8=$ area of building

$\mathrm{X} 9=$ area of vehicle

$\mathrm{X} 10=$ area of humans

$\mathrm{X} 13=$ area of herbaceous foreground material

$\mathrm{X} 14=$ area of wildflowers in foreground

$\mathrm{X} 15=$ area of utilities

$\mathrm{X} 16=$ area of boats

$\mathrm{X} 17=$ area of dead foreground vegetation

X19 $=$ area of wildlife

$\mathrm{X} 30=$ open landscapes $=\mathrm{X} 2+\mathrm{X} 4+(2 *(\mathrm{X} 3+\mathrm{X} 6))$

$\mathrm{X} 31=$ closed landscapes $=\mathrm{X} 2+\mathrm{X} 4+\left(2^{*}(\mathrm{X} 1+\mathrm{X} 17)\right)$

$\mathrm{X} 32=$ openness $=\mathrm{X} 30-\mathrm{X} 31$

$\mathrm{X} 34=$ mystery $=\mathrm{X} 30 * \mathrm{X} 1 * \mathrm{X} 7 / 1140$

$X 52=$ noosphericness $=X 7+X 8+X 9+X 15+X 16$ 


\begin{tabular}{|l|c|}
\hline \multicolumn{2}{|c|}{ Environmental Quality Index } \\
\hline Variable & Score \\
\hline A. Purifies Air & $+10-1$ \\
\hline B. Purifies Water & $+10-1$ \\
\hline C. Builds Soil Resources & $+10-1$ \\
\hline D. Promotes Human Cultural Diversity & $+10-1$ \\
\hline E. Preserves Natural Resources & $+10-1$ \\
\hline F. Limits Use of Fossil Fuels & $+10-1$ \\
\hline G. Minimizes Radioactive Contamination & $+10-1$ \\
\hline H. Promotes Biological Diversity & $+10-1$ \\
\hline I. Provides Food & $+10-1$ \\
\hline J. Ameliorates Wind & $+10-1$ \\
\hline K. Prevents Soil Erosion & $+10-1$ \\
\hline L. Provides Shade & $+10-1$ \\
\hline M. Presents Pleasant Smells & $+10-1$ \\
\hline N. Presents Pleasant Sounds & $+10-1$ \\
\hline O. Does not Contribute to Global Warming & $+10-1$ \\
\hline P. Contributes to the World Economy & $+10-1$ \\
\hline Q. Accommodates Recycling & $+10-1$ \\
\hline R. Accommodates Multiple Use & $+10-1$ \\
\hline S. Accommodates Low Maintenance & $+10-1$ \\
\hline T. Visually Pleasing & $+10-1$ \\
\hline & \\
\hline
\end{tabular}

Table 1. An index adapted from Smyser (1982) that has been examined as a predictor in visual/environmental quality studies.

In Burley's Equation 1 there is a set of regressors with negative coefficients. Like in Shafer's studies, this set of regressors positively relate to visual quality (Burley, 1997). They include the presence of immediate vegetation and distant non-vegetation, the presence of wildlife, the presence of flowers and the presence of openness (X1, X6, X14, X19 and X32). Images containing these features may score in the $40 \mathrm{~s}$ or $30 \mathrm{~s}$. These regressors are perceived as positive enhancements by respondents. There is also a set of regressors with positive coefficients (Burley, 1997). This set of regressors are strongly associated with poor visual quality (Burley, 1997). These regressors include the presence of vehicles, humans, utility structures and overall noospheric (man dominated) features (X9, X10, X15 and X52). This means that the more humans, vehicle, building and artificial structures in a photograph or real landscape, the worse the visual quality becomes. Images with abundant noospheric features can score as high as about 110 . There is a third set of variables to be considered: neutral variables (Burley, 1997). Typical neutral variables are sky, clouds, sun, moon, water, ice, snow and so on. They affect the presence of both positive and negative variables. The more area these neutral variables occupy in a photograph, the more likely the score is close to a neutral value, which is 70 . Figures 3 and 4 present examples of images where equation 1 has been applied to the image with resulting scores. 


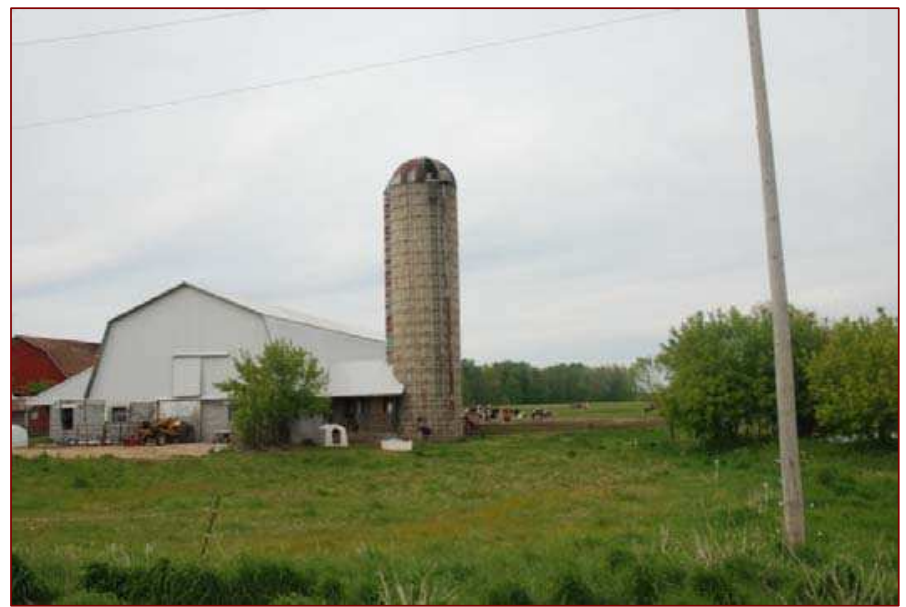

Fig. 3. A farmland image with a predictive score of 56.356 - Copyright $@ 2010$, Di Lu, all rights reserved, used by permission.

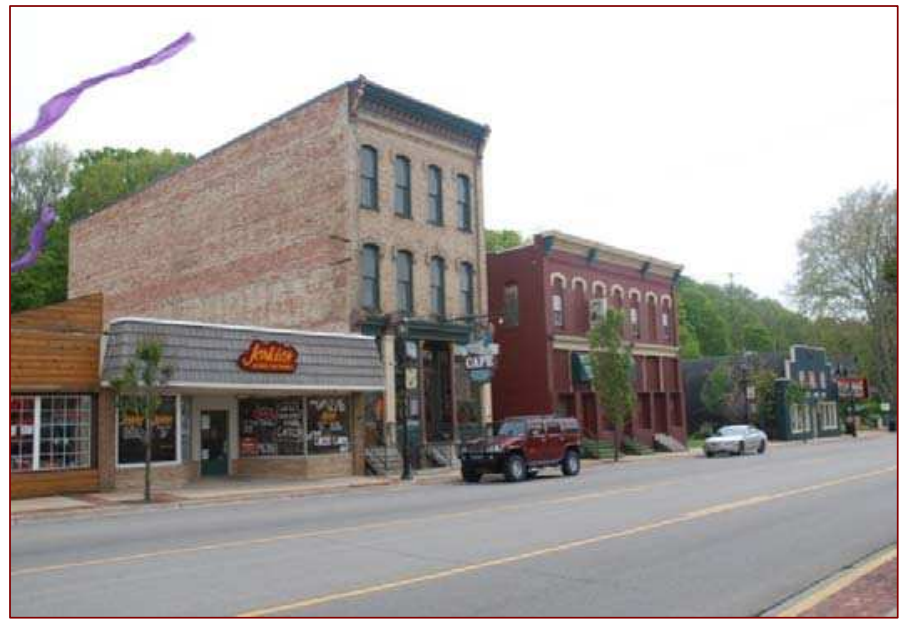

Fig. 4. A typical downtown image with the score of 80.4456 - Copyright (C) 2010, Di Lu, all rights reserved, used by permission.

Another feature of the equation is the inclusion of cultural, economic, and ecological variables in an index derived from the work of Carol Smyser (1982) (Table 1). This index has not been employed as a potential regressor by others as most investigators emphasized to test somewhat aesthetic physical variables, not culture, economics, nor ecology. When the index is included in statistical analysis, it usually is one of the more important variables to predict visual quality for North Americans, French, and Portuguese respondents (Mo et al., 2010). Since the index is more than just a visual measure and includes other environmental considerations, investigators have begun to reconsider the values and perception of respondents. When respondents examine and 
experience the environment, they appear not to separate a mixture of aesthetic, cultural, economic, and ecological criteria and instead appear to consider the complete environmental Gestalt of the image or space. Because the respondents seem to be considering more than just aesthetic criteria, metrics such as the one by Burley (1997) seem to be a combination of aesthetic and other environmental assessments. Nevertheless, the Smyser derived index still is a somewhat qualitative index; yet when applied and tested with groups of over 100 respondents in the years 1985, 1992, 1993, 1994, 2009, and 2010 to examine the variability of the index, respondents usually are within plus or minus 2 points when employing the index. In addition, the collective mean scores for each year that the index was examined are within decimal points of each other. Thus the index seems to have some surprising consistency.

With the equation, it is possible to compare various photographs by constructing a plot of the predicted mean score for a statistical equation and then calculating the $95 \%$ confidence tables for the mean scores (Burley, 1997). A graph was constructed to illustrate the confidence plots (Figure 5). Comparisons between scores from various images were made horizontally by determining whether there is an overlap between the two tails (Burley, 1997). The confidence tails for Figures 3 and 4 do not overlap in Figure 5, and thus it is possible to conclude the two images are significantly different.

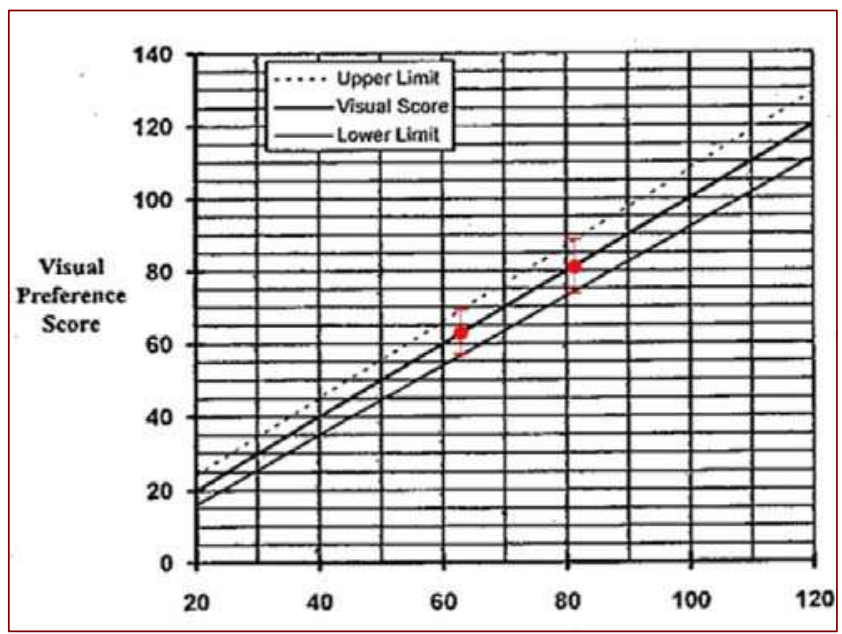

Fig. 5. A comparison of the images in Figures 3 and 4.

With the equation presented by Burley, the intent of the study was to see if this equation could be used to create a map and then test the validity of the map. To create the map, the visual quality scores of the first set of photographs were measured and matched to landuses. The average visual quality score for each land-use type generated a map of average predicted visual quality scores for the study area (Figure 6). The GPS locations of the second set of images allowed one to determine the predicted score on the map for these locations. Then the predicted and actual score could be compared. The statistical analysis between the two sets of scores can be conducted using Kendall's Coefficient of Concordance $(W)$ (Daniel, 1978), one of the few tests for similar agreement (significant similarity). The test is a 
nonparametric test and quite flexible in use and application. The test uses simple algebra and can be computed on a spreadsheet.

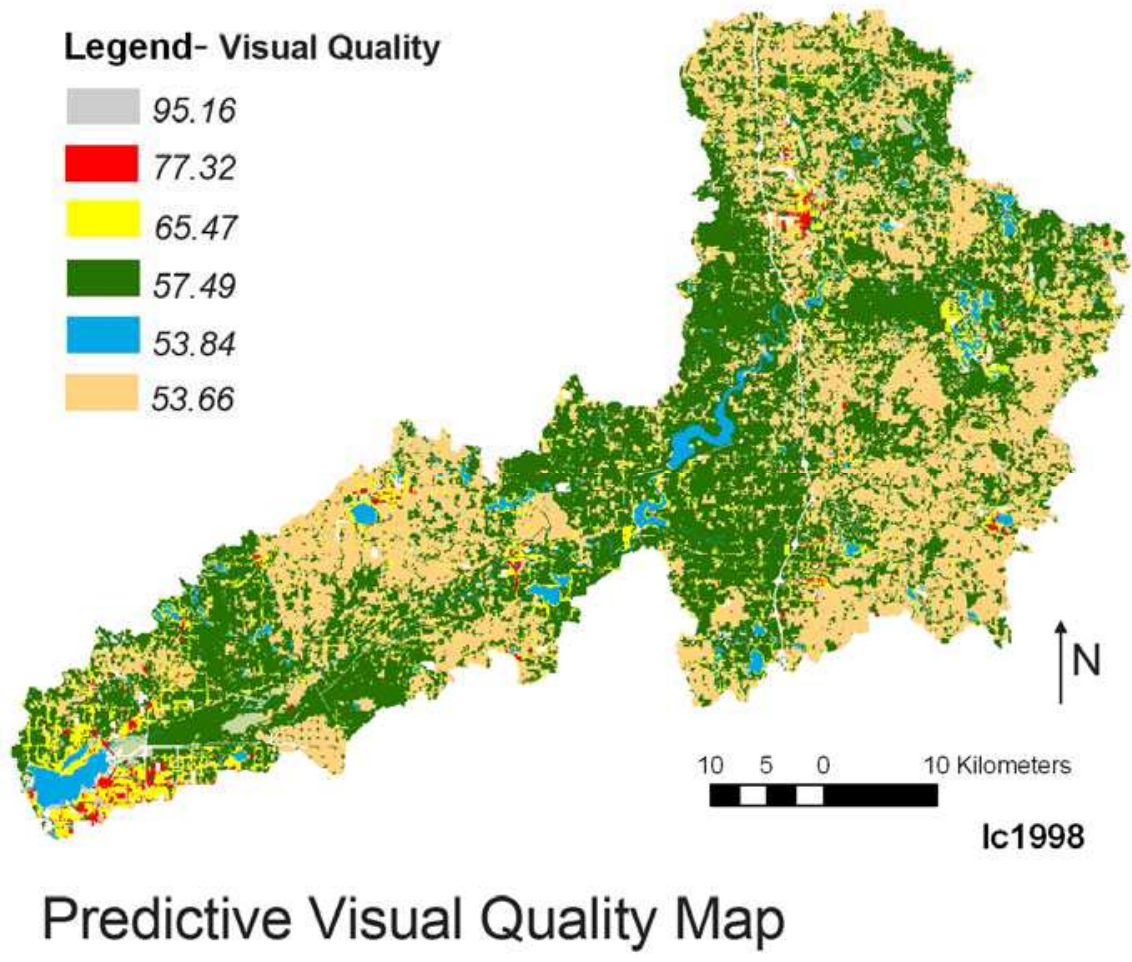

Fig. 6. A map of predicted visual/environmental quality scores for the lower Muskegon watershed. Lower values indicate better quality, higher scores indicate poor quality.

Suppose that a score $i$ is given the rank $r_{i, j}$ by treatment number $j$, where there are in total $n$ scores per treatment and $m$ treatments. In our case there are 30 images $(n=30)$ in each treatment $(n=2)$ where predicted map score and the score when measuring the photograph with an equation represent the treatments. Then the total rank $\left(R_{j}\right)$ given to a treatment is the sum of the ranks for a treatment. Then computationally the test statistic $\mathrm{W}$ is computed in equation 2.

$$
W=12 \sum_{j=1}^{n}\left(R_{j}\right)^{2}-\left[3 m^{2} n(n+1)^{2}\right] /\left[m^{2} n\left(n^{2}-1\right)\right]
$$

The test statistic $W$ is between 0 and 1 . If $W$ is 0 , there is no overall trend of agreement among the respondents. If $W$ is 1 , the responses might be regarded as essentially unanimous. Intermediate values of $W$ suggest a degree of concordance among different responses. $W$ approximates a Chi-square statistic with n-1 degrees of freedom, as illustrated in equation 3 .

$$
X^{2}=m(n-1) W
$$


Quantitative Methods in Environmental and Visual Quality Mapping and

\begin{tabular}{|c|c|c|c|c|}
\hline $\begin{array}{l}\text { Set Two } \\
\text { Image NO. }\end{array}$ & $\begin{array}{c}\text { Measured } \\
\text { Score }\end{array}$ & $\begin{array}{c}\text { Measured } \\
\text { Score's } \\
\text { Ranking }\end{array}$ & $\begin{array}{c}\text { Predictive Score } \\
\text { From A Map }\end{array}$ & $\begin{array}{c}\text { Predictive Score's } \\
\text { Ranking }\end{array}$ \\
\hline 21 & 107.805 & 1 & 95.160185 & 1.5 \\
\hline 4 & 93.2968 & 2 & 95.160185 & 1.5 \\
\hline 28 & 83.52013 & 3 & 77.32490333 & 4 \\
\hline 22 & 81.84413 & 4 & 77.32490333 & 4 \\
\hline 11 & 80.84248 & 5 & 77.32490333 & 4 \\
\hline 26 & 73.11433 & 6 & 65.46785333 & 7.5 \\
\hline 16 & 72.98182 & 7 & 65.46785333 & 7.5 \\
\hline 1 & 72.91732 & 8 & 65.46785333 & 7.5 \\
\hline 30 & 68.89192 & 9 & 58.92745 & 10 \\
\hline 24 & 67.92477 & 10 & 65.46785333 & 7.5 \\
\hline 20 & 61.07647 & 11 & 53.83573333 & 17.5 \\
\hline 2 & 60.12997 & 12 & 53.660695 & 26 \\
\hline 17 & 59.10933 & 13 & 53.660695 & 26 \\
\hline 13 & 56.192 & 14 & 57.478774 & 12 \\
\hline 14 & 55.29468 & 15 & 53.660695 & 26 \\
\hline 18 & 54.71145 & 16 & 57.478774 & 12 \\
\hline 3 & 54.04903 & 17 & 53.83573333 & 17.5 \\
\hline 7 & 52.3262 & 18 & 57.478774 & 12 \\
\hline 10 & 51.93535 & 19 & 53.660695 & 26 \\
\hline 8 & 51.06412 & 20 & 53.660695 & 26 \\
\hline 19 & 50.506 & 21 & 53.83573333 & 17.5 \\
\hline 12 & 48.79608 & 22 & 53.660695 & 26 \\
\hline 27 & 48.7268 & 23 & 53.83573333 & 17.5 \\
\hline 15 & 48.2258 & 24 & 53.660695 & 26 \\
\hline 29 & 48.1872 & 25 & 53.83573333 & 17.5 \\
\hline 25 & 46.87449 & 26 & 53.83573333 & 17.5 \\
\hline 6 & 44.4542 & 27 & 53.83573333 & 17.5 \\
\hline 5 & 43.3638 & 28 & 53.660695 & 26 \\
\hline 9 & 42.1124 & 29 & 53.83573333 & 17.5 \\
\hline 23 & 41.91216 & 30 & 53.660695 & 26 \\
\hline
\end{tabular}

Table 2. The scores and the rankings of the measured images and the predicted scores and rankings derived from a map.

In Table 2 the measured scores are ranked from high to low, with 107.805 assigned as the highest score and 41.91216 assigned as the lowest score for the measured images; while the predictive map scores are ranked according to corresponding expected value based upon land-use/land-cover. In Kendall's Coefficient of Concordance, a W value of 0.851112347 was generated. A corresponding Chi-Square table was consulted to determine if the derived value for Chi-Square was significant $(\mathrm{p} \leq 0.05)$ at twenty-nine degrees of freedom (Daniel, 1978). Since the derived value of 49.36 is greater than the table value of 42.56 , the null hypothesis was rejected and the hypothesis that the two sets of numbers are in concordance $(\mathrm{p} \leq 0.05)$ was accepted. It was determined, through statistical analysis, that the relationship 
of predictions (land-use map based scores) and the real photographs are in concordance and significant to a (95\%) confidence level. In other words, for the study area, it was possible to generate a map that was relatively reliable and one could predict the visual/environmental quality of a place without actually having been there. Rather, based upon a sample of the study area, the visual/environmental quality can be predicted with some level of assurance.

In this research investigation, many more photographic samples could be taken to create a landscape visual quality map; but for this research we were more interested in determining if only a few (30) number of images would generate significant results. The reason was that by using fewer photos, this research could examine the methodology to test for significant concordance $(95 \%)$ under less than ideal data collection conditions, but if this sample indicated significant results, it was then possible to save money and time to create maps with only small sample sizes. Thus, only 30 pairs of images were chosen but with high variation (from rural to urban landscape) to test the ability of the methodology in assessing landscape visual quality. The results suggest that this methodology has practical possibilities to quantitatively and reliably measure the environment.

\section{Urban planning applications}

Many previous investigations demonstrated the validity of using surveys, such as respondent groups in landscape evaluation experiments. Nevertheless, in this experiment, no respondent group was employed to evaluate landscape images, although the equation utilized (Burley's Equation 1) was generated from a respondent group study (Burley, 1997). For planning and design studies and assessment, it might be faster and just as reliable not to gather more information with people-based surveys, but rather rely upon previous research results and predictive models.

In the context of landscape planning and design, landscape visual quality assessments are sometimes considered not important because they lack substantial evidence or due to their subjectivity. The GIS based land use-map might be used in this context to facilitate a reinforcement of visual quality assessment concerning aesthetic changes in the environment. The results of this study suggests that a GIS based land-use map could serve in visual quality assessment as well as in the professional practices of landscape planning. Land-use maps could be used to measure landscape quality instead of real images. With the help of GIS based land-use maps, initial site surveys might be reduced. Designers and planners are able to use predictive equations and GIS data during the early design and assessment phases. However, predicting site-assessed visual quality does not mean that replacing public and expert assessment is always advocated. Instead these procedures are a tool to gage the impact of planning, design, and management impacts.

In an environmental impact assessment, visual quality assessment is an important factor as well. Many of the environment impact properties could not be measured easily because these indicators are very subjective. With the help of GIS based land-use maps to predict potential visual impact, it might supply a quantitative method for environmental impact assessment. For example, as it is known that the predictive visual quality score of farmland is significantly better than the predictive score of industry in Lower Muskegon Watershed. If the developers initiate to build a factory at a farmland area of Lower Muskegon Watershed, it is obvious that the report of visual impact assessment would be negative according to the predictive model presented in this study. 
The results of the experiment could also help manage viewsheds. A viewshed is an area of land, water, or other environmental element that is visible to the human eye from a fixed vantage point. In this paper, the area covered by each recorded photograph is defined as a viewshed. As well as illustrated in this example, all the photo data collected and located in this paper could be used for later viewsheds management research.

While the equation explains a fair amount of variance and can be applied quantitatively, the regressors are not necessarily fixed. New equations may arise with more predictive power and with a different set of regressors. In combination with the equations, general principles and guidelines as the ones reported by Burley (2006a), Kaplan et al., (1998), and Kaplan and Kaplan (1989) may be more helpful to planners and designers in creating and managing the environment than numerical equations. The equations are simply numerical affirmations of these general ideas and recommendations.

For urban planning applications, the most basic application would be to compare images between before and proposed design treatments from key or important viewpoints. The quantitative measure could indicate which treatments perceptually increase the quality of the environment. This technique is explained by Mazure and Burley (2009) and also illustrated by Burley (2006b), but in a more rural setting. For historic preservation purposes, improving the quality may not always be appropriate but to rather maintain a specific quality of an historic setting. Then the quantitative measure could be employed to test treatments for maintaining a specific perceived condition.

In urban settings, sectors of the city could be mapped to establish a base-line and monitor urban environmental quality in the same manner other environmental characteristics are mapped and evaluated. This approach could also be employed at the site/parcel level. Numerical goals and objectives could be established in development plans to maintain a specific level of visual/environmental quality. In addition, the quantitative method could be employed to evaluate corridor/experiential plans and proposals. Kendall's Coefficient of Concordance can be used to test for significant similarity and Friedman's Analysis of Variance (Daniel, 1978) can test for significant differences between plans and treatments. There may be numerous practical approaches to aid the planner and design in crafting the design and management of urban places. However, time will tell whether this integration of social science methods, landscape metrics, and statistical tests will yield productive results in the planning and design area. Many researchers have hope and aspirations for their work, yet often it remains unrealized.

\section{Conclusion}

The development of measuring aesthetic/environmental quality has made progress over the past 50 years. Investigators now understand and can predict about $65 \%$ to $70 \%$ of the variance concerning respondent perception to the spatial quality of the environment. In addition, it is possible to create statistically reliable maps to predict visual quality across the urban and rural environment. The process is relatively efficient and effective. Planners, designers, and citizens can measure the perceived effects of spatial treatments and can assess the perceived impact of various proposals and plans. This approach is one more tool in a toolbox of expert and statistical measures to understand the impacts proposals and plans may have upon the environment. 


\section{Acknowledgements}

The authors wish to thank Wang Sihui a graduate of Nanjing Forestry University and the Masters of Arts in Environmental Design at Michigan State University for her GIS assistance, Grand Valley State University for creating a current land-use map that made this study possible, to Dr. Trisha Machemer from the School of Planning, Design, and Construction at Michigan State University for allowing access to her GIS database, and to Shawn Partin for his advice during his review of the manuscript.

\section{References}

Arriaza, M., Cañas-Ortega, J., Cañas-Madueño, J., \& Ruiz-Aviles, P. (2004). Assessing the visual quality of rural landscapes. Landscape and Urban Planning, Vol.69, No.1, pp. 115-125, ISSN 0169-2046

Bourassa, S.C. (1991). The Aesthetic of Landscape, Belhaven Press, ISBN 1852930713, London, UK

Boster, R.S., \& T. C. Daniel. (1972). Measuring public responses to vegetation management. 16th Annual Arizona Watershed Symposium Proceedings, Arizona Water Commission, Phoenix, Arizona, September 20, 1972, Phoenix, AZ Report Number 2, pp. 38-43.

Brush, R.O., \& Shafer E.L. (1975). Application of a landscape-preference model to land management. In: Landscape Assessment: Values, Perceptions, and Resources, Zube, E.H., R.O. Brush, R.O., \& and Fabos J.G., pp. 168-182, Dowden, Hutchinson and Ross, Inc., ISBN 0-470-98423-6, Stroudsburg, Pennsylvania, USA

Bureau of Land Management. (1980). Visual Resource Management Program, Department of Interior, Bureau of Land Management, Division of Recreation and Cultural Resources, Washington, D.C.

Burley, J.B. (1997). Visual and ecological environmental quality model for transportation planning and design. Transportation Research Record, Vol.1549, pp. 54-60, ISSN 0361198

Burley, J.B. (2006a). The science of design: green vegetation and flowering plants do make a difference: quantifying visual quality. The Michigan Landscape Vol.49, No.8, pp. 2730.

Burley, J.B. (2006b). A quantitative method to assess aesthetic/environmental quality for spatial surface mine planning and design. WSEAS Transactions on Environment and Development, Vol.5, No.2, pp. 524-529, ISSN 17905079

Carlson, A. (1977). On the possibility of quantifying scenic beauty. Landscape Planning, Vol.4, No.2, pp. 131-172, ISSN 0169-2046

Crawford, D. 1994. Using remotely sensed data in landscape visual quality assessment. Landscape and Urban Planning, Vol.30, No.1-2, pp 71-81, ISSN 0169-2046

Daniel, W.W. (1978). Applied Nonparametric Statistics, Houghton Mifflin Company, ISBN 0395-25795-6, Boston, Massachusetts, USA

Fuente de Val, G., Atauri, J. \& de Lucio, J. (2006). Relationship between landscape visual attributes and spatial pattern indices: A test study in Mediterranean-climate landscapes. Landscape and Urban Planning, Vol. 77, No. 4, pp. 393-407, ISSN 01692046

Kaplan, R., \& Kaplan S. (1989). The Experience of Nature: A Psychological Perspective, Cambridge University Press, ISBN 0521341396, Cambridge, UK 
Kaplan, R., Kaplan, S., \& Ryan, R. (1998). With People in Mind: Design and Management of Everyday Nature, Island Press, ISBN 1559635940, Washington, D.C., USA

Lee, E.J., \& Burley, J.B. (2008). Assessing visual quality change 25 years after post-mining housing development in Plymouth, Minnesota, New Opportunities to Apply Our Science, 2008 National Meeting of the American Society of Mining and Reclamation, Richmond, VA,June 14-19, 2008, R.I. Barnhisel (Ed.) American Society for Mining and Reclamation, Lexington, Kentucky, USA

Loures, L., Vargues, P., Horta, D. (2008). Landscape aesthetical and visual analysis facing the challenge of the development of sustainable landscapes - the case study of the post-industrial area to the left margin of the Arade River. International Journal of Design \& Nature and Ecodynamics, Vol.3, No.1, pp. 65-74, ISSN: 1755-7445

Lu, Di. (2011). Visual Quality Assessment at the Lower Muskegon Watershed, Masters of Arts in Environmental Design Thesis, Michigan State University, E. Lansing, Michigan, USA

Mazure, A., \& Burley, J.B. (Chinese translation by Wang H., \& S. Wang, S.) (2009). Balancing art and science of landscape architecture: hand-drawing in China and computeraided visual quality assessment in Michigan. Journal of Nanjing Forestry University (Humanities and Social Sciences Edition), Vol.9, No.2, pp. 84-93, ISSN 1671-1165

Mo, F., Le Cléach, G., Sales, M., Deyoung, G. and Burley, J.B. (2011). Visual and environmental quality perception and preference in the People's Republic of China, France, and Portugal. International Journal of Energy and Environment, Vol.5, No.4, pp 549-555, ISSN 2076-2895

Panagopoulos, T., \& Vargues, P.M. (2006). Visual impact assessment of a golf course in a Mediterranean forest landscape. In: Patterns and Processes in Forest Landscapes, Consequences of Human Management, Lafortortezza, L., Sanesi, G., pp. 279-285, Accademia Italiana di Scienze Florestali, Firenze, Italy

Shafer, E. Jr. (1969). Perception of natural environments. Environment and Behavior, Vol.1, No.1, pp. 71-82, ISSN 0013-9165

Shafer Jr., E., Hamilton Jr., J.F., \& Schmidt, E.A. (1969). Natural landscape preference: a predictive model. Journal of Leisure Research, Vol.1, pp. 1-19, ISSN 0022-2216

Shafer Jr., E., \& Tooby, M. (1973). Landscape preference: an international replication. Journal of Leisure Research, Vol.5, pp. 60-65, ISSN 0022-2216.

Schauman, S., \& Adams, C. (1979). Soil conservation service landscape resource management. Proceedings of our national landscape: a conference on applied techniques for analysis and management of the visual resource [Incline Village, Nev., April 23-25, 1979], Elsner, G. H., \& Smardon, R. C. (technical coordinators), pp 671-673, General Technical Report PSW-GTR-35. Berkeley, CA, Pacific Southwest Forest and Range Experiment Station, Forest Service, U.S. Department of Agriculture,

Smardon, R., Palmer, J., \& Felleman, J. (1986). Foundations for Visual Project Analysis, A Wiley-Interscience Publication, ISBN 0471881848, New York, New York

Smyser, C. (1982). Nature's Design: A Practical Guide To Natural Landscaping, Rodale Press, ISBN 9780878573431, Emmaus, Pennsylvania

Taylor, J. G., Zube, E. H., \& Sell., J. L. (1987). Landscape assessment and perception research methods, In: Methods in Environmental and Behavioral Research, Bechtel, R.B., Marans, R.W., \& William Michelson, W., p. 361-393, Van Nostrand Reinhold Company, ISBN 0442222570, New York, New York. 
United State Forest Service. (1973). National Forest Landscape Management, U.S. Department of Agriculture, Agriculture Handbook no. 434, U.S. Government Printing Office, Washington, D.C.

Van den Berg, A.E. \& Koole, S. (2006). New wilderness in the Netherlands: An investigation of visual preferences for nature development landscapes. Landscape and Urban Planning, Vol.78, No.4, pp. 362-372, ISSN 0169-2046

Weinstein, N.D. (1976). The statistical prediction of environmental preferences: problems of validity and application. Environment and Behavior, Vol.8, No.4, pp. 611-626, ISSN 0013-9165

Zube, E.H. (1974). Cross-disciplinary and intermode agreement on the description and evaluation of landscape resource. Environment and Behavior, Vol.6, pp. 69-89, ISSN 0013-9165

Zube, E.H., Sell, J.L., \& Taylor, J.G. (1982). Landscape perception: research, application and theory. Landscape Planning, Vol.9, pp. 1-33, ISSN 0169-2046 


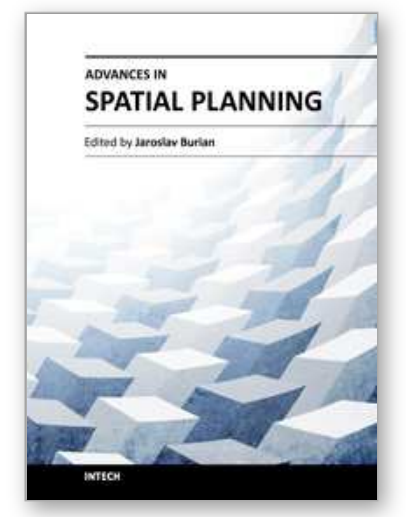

\author{
Advances in Spatial Planning \\ Edited by Dr Jaroslav Burian
}

ISBN 978-953-51-0377-6

Hard cover, 366 pages

Publisher InTech

Published online 21, March, 2012

Published in print edition March, 2012

Spatial planning is a significant part of geosciences that is developing very rapidly. Many new methods and modeling techniques like GIS (Geographical Information Systems), GPS (Global Positioning Systems) or remote sensing techniques have been developed and applied in various aspects of spatial planning. The chapters collected in this book present an excellent profile of the current state of theories, data, analysis methods and modeling techniques used in several case studies. The book is divided into three main parts (Theoretical aspects of spatial planning, Quantitative and computer spatial planning methods and Practical applications of spatial planning) that cover the latest advances in urban, city and spatial planning. The book also shows different aspects of spatial planning and different approaches to case studies in several countries.

\title{
How to reference
}

In order to correctly reference this scholarly work, feel free to copy and paste the following:

Di Lu, Jon Burley, Pat Crawford, Robert Schutzki and Luis Loures (2012). Quantitative Methods in Environmental and Visual Quality Mapping and Assessment: A Muskegon, Michigan Watershed Case Study with Urban Planning Implications, Advances in Spatial Planning, Dr Jaroslav Burian (Ed.), ISBN: 978-953-510377-6, InTech, Available from: http://www.intechopen.com/books/advances-in-spatial-planning/quantitativemethods-in-environmental-and-visual-quality-mapping-and-assessment-a-muskegon-michigan-

\section{INTECH}

open science | open minds

\author{
InTech Europe \\ University Campus STeP Ri \\ Slavka Krautzeka 83/A \\ 51000 Rijeka, Croatia \\ Phone: +385 (51) 770447 \\ Fax: +385 (51) 686166 \\ www.intechopen.com
}

\author{
InTech China \\ Unit 405, Office Block, Hotel Equatorial Shanghai \\ No.65, Yan An Road (West), Shanghai, 200040, China \\ 中国上海市延安西路65号上海国际贵都大饭店办公楼405单元 \\ Phone: +86-21-62489820 \\ Fax: +86-21-62489821
}


(C) 2012 The Author(s). Licensee IntechOpen. This is an open access article distributed under the terms of the Creative Commons Attribution 3.0 License, which permits unrestricted use, distribution, and reproduction in any medium, provided the original work is properly cited. 